\title{
A Paideia: Cultura, Cibercultura e a Educação à
}

\section{Distância.}

Juliana Savoy Fornari ${ }^{1}$

\section{Resumo}

Apresenta os fundamentos históricos do conceito de Educação Integral e do alcance dessa expressão na Filosofia da Educação e na dimensão política do termo. Debate as questões de Educação de Tempo Integral analisando as teorias e práticas de ampliação de jornadas na organização da Educação e da Escola no Brasil, decorrente dos modelos ocidentais. Apresenta as principais experiências de Educação Integral e de organização de Escolas de Tempo Integral no Brasil e explora suas originalidades, suas características e suas contradições. Apresenta a possibilidade de uma política de Educação Integral em Escolas de Tempo Integral a partir da concepção da Educação como Direito ou do Direito à Educação, contextualizando tal possibilidade no ciclo de atuação política aberto pela eleição de Luis Inácio Lula da Silva e Dilma Rousself na política brasileira. Destaca as novas ordenações jurídicas da sociedade brasileira e aponta para a possibilidade de uma Nova Educação Integral.

Palavras-chave: Educação integral. Filosofia. Emancipação. Ética.

\section{Resumen}

Presenta los fundamentos historicos del concepto de Educación Integral y del alcance de esa expresión en la Filosofía de la Educación y en la dimensión política del término. Debate las cuestiones de Educación de Tiempo Integral analizando las teorías y prácticas de ampliación de jornadas en la organización de la Educación y la Escuela en Brasil, derivada de los modelos occidentales. Presenta las principales experiencias de Educación Integral y de organización de Escuelas de Tiempo Integral en Brasil y explora sus originalidades, sus características y suyas contradicciones. En el marco de la política de educación integral en las escuelas de tiempo completo a partir de la concepción de la Educación como Derecho o del Derecho a la Educación, contextualizando tal posibilidad en el ciclo de actuación política abierto por la elección de Luis Inacio Lula da Silva y Dilma Rousself en la política brasileño. Destaca las nuevas ordenaciones jurídicas de la sociedad brasileña y apunta a la posibilidad de una nueva Educación Integral.

Palabras-clave: Educación integral. Filosofía. Emancipación. Ética.

\footnotetext{
${ }^{1}$ Pesquisadora do Grupo de Estudos e Pesquisas PAIDEIA/UNICAMP E-mail: julianas@anchieta.br
} 


\section{Introdução}

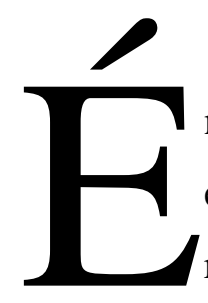

na Grécia que temos os primeiros registros da história da educação com algum sentido social e reflexivo na nossa realidade educativa. São os Gregos quem, pela primeira vez, colocam a educação como um problema e uma instituição da prática social. Já na literatura grega percebemos sinais do questionamento desse conceito, seja na poesia, na tragédia ou na comédia. Mas é no século V a.C., com os Sofistas e depois com Sócrates, Platão, Isócrates e Aristóteles, que o conceito de educação alcança o estatuto de uma questão filosófica. Os ideais educativos da Paideia que vão ser desenvolvidos no século $\mathrm{V}$ a. C. se baseiam em práticas educativas muito anteriores. Como coloca Werner Jaeger, estudioso da cultura grega, em seu estudo intitulado Paideia: "não se pode utilizar a história da palavra Paideia como fio condutor para estudar a origem da educação grega, porque esta palavra só aparece no século $V^{\prime \prime}$ (Jaeger, 1986).

Ainda assim utilizaremos o conceito de Paideia como objetivo central deste estudo, pois nessa consideração da formação histórica da metodologia da filosofia da educação, nos vimos concentrando nos discursos hegemônicos na tradição ocidental. Sendo a Paideia o conceito hegemônico dominante na historia da educação, este atende o nosso objetivo na constituição do conceito de teoria e prática diacrônica de como se organizaram os discursos da educação na história.

Inicialmente, a palavra Paideia (Paideia de origem paidos - paidos criança) significava simplesmente "criação dos meninos". Mas, como veremos, este significado inicial da palavra está muito longe do elevado sentido que mais tarde adquiriu. $\mathrm{O}$ conceito que originalmente exprime o ideal educativo grego é o de aretê. Originalmente formulado e explicitado nos poemas homéricos, a aretê é entendida como um atributo próprio da nobreza, um conjunto de qualidades físicas, espirituais e morais tais como a bravura, a coragem, a força, a destreza, a eloquência, a capacidade de 
persuasão, numa palavra, a heroicidade.

$\mathrm{O}$ alargamento do ideal educativo de aretê surgiu nos fins da época arcaica, exprimindo-se então pela palavra kaloskagathia. Mais que honra e glória, pretende-se então alcançar a excelência física e moral. Os atributos que o homem deve procurar realizar são a beleza (kalos) e a bondade (kagatos). Para alcançar este ideal é proposto um programa educativo que implica dois elementos fundamentais: a ginástica para o desenvolvimento do corpo, e a música (aliada à leitura e ao canto) para o desenvolvimento da alma. No fim da época arcaica, este programa educativo completava-se com a gramática. Mas, se até então o objetivo fundamental da educação era a formação do homem individual como kaloskagathos, a partir do século $\mathrm{V}$ a. C., exige-se algo mais da educação. Para além de formar o homem, a educação deve ainda formar o cidadão. A antiga educação, baseada na ginástica, na música e na gramática deixa de ser suficiente.

É então que o ideal educativo grego aparece como Paideia, formação geral que tem por tarefa construir o homem como homem e como cidadão. Platão define Paideia da seguinte forma "(...) a essência de toda a verdadeira educação ou Paideia é a que dá ao homem o desejo e a ânsia de se tornar um cidadão perfeito e o ensina a mandar e a obedecer, tendo a justiça como fundamento" (cit. in Jaeger, 1986: 147).

Do significado original da palavra Paideia como criação dos meninos, o conceito amplia-se para, no século IV. a.C., adquirir a forma cristalizada e definitiva com que foi consagrado como ideal educativo da Grécia clássica. Como diz Jaeger (1986), os gregos deram o nome de Paidéia a "todas as formas e criações espirituais e ao tesouro completo da sua tradição, tal como nós o designamos por Bildung ou pela palavra latina, cultura." Daí que, para traduzir o termo Paideia "não se possa evitar o emprego de expressões modernas como civilização, tradição, literatura ou educação; nenhuma delas coincidindo, porém, com o que os Gregos entendiam por Paideia. Cada um daqueles termos se limita a exprimir um aspecto daquele conceito global. Para abranger o campo total do conceito grego, teríamos de empregá-los todos de uma só vez." (Jaeger, 1986: 1). 
Na sua abrangência, o conceito de Paideia não designa unicamente a técnica própria para, desde cedo, preparar a criança para a vida adulta. A ampliação do conceito fez com que ele passasse também a designar o resultado do processo educativo que se prolonga por toda vida, muito para além dos anos escolares. A Paideia vem por isso a significar "cultura entendida no sentido perfectivo que a palavra tem hoje entre nós: o estado de um espírito plenamente desenvolvido, tendo desabrochado todas as suas virtualidades, o do homem tornado verdadeiramente homem" (Marrou, 1966: 158).

Na Paideia grega, decorrente da formação econômica e política da sociedade ateniense, prevalecia uma teoria da educação que considerava que os homens já nasciam com a carga epistemológica que poderiam ter ou desenvolver. Por isso a educação era voltada para homens, do sexo masculino, da mais alta nobreza, pois acreditava-se que educar era extrair da alma aquilo que já estava lá, tratava-se de um determinismo da alma intelectiva. Tal pensamento foi classificado a posteriori como o inatismo gnosiológico pedagógico, ou seja, a teoria que acredita que as pessoas já nascem, ou não, com a capacidade de aprender as virtudes da Paideia. Ressalta-se, todavia, que o chamado inatismo gnosiológico pedagógico, que falamos, deve ser estudado e compreendido em seu contexto, de como a sociedade daquela época se organizava e dos interesses políticos e econômicos que prevaleciam. Ao fazermos um simples recorte para os dias atuais, perde-se o sentido e podemos incorrer no erro de uma análise vazia.

Apenas com o advento do cristianismo primitivo, nos sec. I, II e III, haverá a quebra na crença no inatismo cognitivo, e a ideia de que todos os homens, homens e mulheres, pobres ou ricos, podem ser salvos, revoluciona a teoria da educação antiga da Paideia Grega e passamos a vivenciar a Paideia cristã. A primeira expressão democrática nasce de Jesus de Nazaré, uma educação democrática e para todos - a minha fé é para todos, todos que quiserem crer terão a minha fé. Dessa forma a definição teórico-prática que a educação é para todos surge com Jesus de Nazaré - personagem que prega que todos que quiserem crer serão salvos. Há diversos estudos que 
destacam esse nova atitude educacional e religiosa, como as pesquisas de Nunes (NUNES, C. 2017).

Assim o Cristianismo inaugura a atitude democrática de acesso à educação como direito de todos. No entanto, a marcha histórica do Cristianismo não é linear, esta é marcada por avanços e contradições. E é na figura de Paulo de Tarso, apóstolo cristão que, depois de convertido, prega o Cristianismo por toda a Ásia Menor fundando as comunidades cristãs de Éfeso, Atenas, Tessalônica, Corinto, Esmirna e muitas outras. Através de Paulo o Cristianismo se sistematiza e se assume entre as mulheres e os pobres, universalizando a ideia de uma educação para todos. Paulo faz três grandes viagens pela Ásia e acaba sendo condenado e morto em Roma. No entanto, em todas as comunidades que pregou e fundou acabou por alimentar através de cartas, que hoje configuram as cartas paulinas, inseridas no Novo Testamento bíblico. As cartas de Paulo eram instrumentos de debate teológico e de preleções morais, de formação cristã e de conversão dos denominados "gentios", os povos "não-judeus", para os quais o Cristianismo abria sua mensagem e suas práticas. O professor César Nunes (NUNES, 2017) assim expressa a originalidade essa atitude política:

As cartas paulinas, que compõem a maioria das cartas do Novo Testamento, são documentos teológicos, mas também são produções didáticas de fundamentos literários brilhantes que mostram a rica metodologia de educação à distância produzida pelo grande missionário e teólogo Paulo de Tarso, endereçadas às igrejas de Corinto, de Éfeso, de Tessalônica, de Roma, da Galácia, para ficar entre as principais. (NUNES, Cesar. 2017, p 52)

No entanto essa igualdade universal que o cristianismo pregava não durou muito tempo, demais pensadores a exemplo de Santo Agostinho com seu pensamento maniqueísta representaram um retrocesso nas ideias de Paulo de Tarso. A continuidade da expansão do Cristianismo e de sua mensagem pode ser entendida como contraditória, com muitos avanços em momentos históricos e outras possíveis etapas de recuos e de desmandos. 


\section{A cibercultura e a urgência da educação a distância.}

No entendimento do conceito de paideia, em seu sentido mais amplo, representando a educação durante toda a vida, e ainda qualificando como a cultura que o homem possa ter e construir durante a sua existência, somado a ideia de democratização da educação, como um direito de todos, onde aqueles que quiserem se educar poderão acessar conhecimento, podemos ousar e dizer que atualmente vivenciamos um grande momento da história, que mais adiante, poderá se caracterizar como uma revolução no que entendemos até hoje como educação e seus limites.

A internet, essa rede de computadores dispersos por todo o planeta que trocam dados e mensagens utilizando um protocolo comum, unindo usuários particulares, entidades de pesquisa, órgãos culturais, institutos militares, bibliotecas e empresas de toda envergadura, passa a modificar a maneira que nos comunicamos, nos relacionamos e principalmente como aprendemos. E neste sentido passamos a desenvolver uma espécie de cibercultura. Esta cibercultura está promovendo novas possibilidades de socialização e aprendizagem mediadas pela rede e, no caso específico da educação, pelos ambientes virtuais de aprendizagem. Santos (2009) conceitua a cibercultura como uma cultura contemporânea estruturada pelas tecnologias digitais.

De fato, não é uma utopia, é o presente; vivemos uma cultura estruturada pelas tecnologias digitais, seja como autores e atores incluídos no acesso e uso criativo das tecnologias de informação e comunicação (TICs), seja como excluídos digitais, que se recusam compartilhar experiências neste espaço. Destaca-se o conceito de Lemos (2003), que expõe em seus estudos a cibercultura como a forma sociocultural que emerge da relação simbiótica entre sociedade, a cultura e as novas tecnologias que surgiram com a convergência das telecomunicações com a informática na década de 1970 do século passado. Podemos assim entender que a educação a distância (EAD) é um fenômeno da cibercultura, que 
educar através de ambientes virtuais, utilizando tecnologia de informação e mídias digitais é um possível caminho democrático para atingir a maior parte de pessoas interessadas em adquirir conhecimentos e formação acadêmica, cultural e profissional.

A educação a distância (EAD), segundo Santos (2009), é o conjunto de ações de ensino-aprendizagem ou atos de currículo mediados por interfaces digitais que potencializam práticas comunicacionais interativas. Cada vez mais sujeitos e grupos-sujeito, empresas, organizações, enfim, espaços multirreferenciais de aprendizagem vêm lançando mão desse conceito e promovendo a disseminação cultural de suas ideias, potencializando a democratização da informação, da comunicação e da aprendizagem entre indivíduos geograficamente dispersos seja como elemento potencializador da educação presencial e ou da educação a distância. As tecnologias digitais mais utilizadas nas atuais práticas de educação a distância são os ambientes virtuais de aprendizagem (AVAs), as

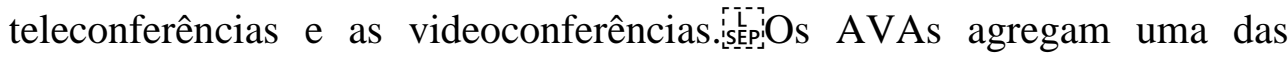
características preponderante da internet: a convergência de mídias, ou seja, a capacidade de hibridizar e trocar num mesmo ambiente várias mídias. Mídia é todo o suporte que veicula a mensagem expressada por uma multiplicidade de linguagens (sons, imagens, gráficos, textos em geral). Os ambientes virtuais de aprendizagem envolvem não só um conjunto de interfaces para socialização de informação, de conteúdos de ensino e aprendizagem, mas também, e, sobretudo, as interfaces de comunicação síncronas e assíncronas.

A classificação “interfaces de conteúdos” e “interfaces de comunicação" é utilizada por nós apenas por conta de uma organização conceitual. Caracteriza-se de interfaces de conteúdos os dispositivos que permitem produzir, disponibilizar, compartilhar conteúdos digitalizados em diversas linguagens: texto, som, imagem. E as interfaces de comunicação são àquelas que contemplam a troca de mensagens entre os interlocutores do grupo ou da comunidade de aprendizagem. Estas podem ser síncronas, isto é, contemplam a comunicação em tempo real (exemplos: chats, 
webconferências, entre outras), podendo haver uma interatividade maior entre os atores. Ou assíncronas, isto é, permitem a comunicação em tempos diferentes (exemplos: fóruns, listas de discussão, blogs e wikis entre outras), sem interatividade imediata.

Nas interfaces síncronas e assíncronas conteúdo e comunicação são elementos imbricados, não podemos entender os conteúdos apenas como informações para estudo ou material didático construído previamente ou ao longo do processo de ensino-aprendizagem. Além disso, não podemos negar que conteúdos são gerados a partir do momento que os interlocutores produzem sentidos e significados pelas interfaces síncronas e assíncronas.

$\mathrm{Na}$ verdade, a construção do conhecimento, nas interfaces digitais, ocorre pela interação dos interlocutores por meio da análise crítica das informações expostas no AVA. A apropriação adequada dessas interfaces permite produzir conhecimentos num processo de autoria e co-criação. $\mathrm{O}$ AVA apresenta-se como uma organização viva, em que seres humanos e objetos técnicos interagem num processo complexo que se auto-organiza na dinâmica dialógica de suas redes de conexões (SANTOS, 2009). Nas práticas mais antigas e convencionais de EAD, temos a autoaprendizagem como característica principal, ou seja, o aluno recebe o material do curso com instruções que envolvem conteúdos e atividades, elabora sua produção individual retornando-a, via canais de feedback, ao professor-tutor. Neste caso a aprendizagem é construída e mediada pelo material didático produzido à luz de um desenho instrucional. A instrução unidirecional é o centro do processo. O sujeito aprende a partir de si, assimilando as informações e os conhecimentos didaticamente disponibilizados e no seu próprio ordenamento de tempo.

Porém, com a popularização das chamadas mídias sociais, representadas principalmente pelo facebook, instagran e whatsapp, onde as relações se dão muitas vezes de maneira síncrona e ativa, a educação a distância passa a se estruturar de maneira a privilegiar a interatividade e à aprendizagem colaborativa. Além da autoaprendizagem, as interfaces dos AVAs permitem a interatividade e a aprendizagem colaborativa. $\mathrm{O}$ aluno 
aprende com o material didático e na dialógica com outros sujeitos envolvidos como demais professores, tutores e outros alunos, através de processos de comunicação síncronos e assíncronos. A cibercultura se constitui dessas novas possibilidades de socialização e aprendizagem mediadas pelo ciberespaço, a internet, e no caso específico da educação formal pelos AVAs. Nesse sentido, é fundamental nos preocuparmos com a organização do projeto educacional que contemple as potencialidades do hipertexto, da interatividade e da simulação nestes novos espaços do saber. Potencialidades estas que não são excludentes entre si e que não são conceitos emergentes da cibercultura, mas que são por ela potencializados.

As potencialidades das TICs no contexto dos AVA estruturam práticas de qualidade em educação online. Ressaltamos que os conceitos de interatividade, hipertexto e simulação não emergem exclusivamente com o advento das TICs, entretanto, é no contexto da cibercultura que ganham potencialidade por conta da plasticidade do digital. As interfaces de conteúdo e de comunicação dos AVA permitem interatividade e autoria (SANTOS, 2009).

Segundo Silva (2000), interatividade é um conceito da comunicação e não da informática, isto é, ele entende a interatividade como atitude intencional no ato de se comunicar com o outro. Isso significa que os sujeitos da comunicação co-criam a mensagem. É preciso que cada sujeito faça intervenção física nas mensagens. Não há interatividade no ambiente virtual se os sujeitos da comunicação não se autorizarem. Portanto, para que haja interatividade, não basta apenas disponibilizar as interfaces. Mais do que isso, é preciso que os sujeitos comuniquem de fato.

Os produtos culturais que emergem da autoria e da comunicação interativa são em potência hipertextos, isto é, textos que se conectam a outros textos através dos diversos sentidos que são criados nos contextos dos AVAs. Além da hipertextualidade construída nas interfaces de comunicação, os docentes podem se apropriar das interfaces de conteúdos arquitetando o material didático não linear. As interfaces de conteúdo permitem agregar e fazer convergir diversas linguagens (som, imagem, 
gráfico, vídeo) e mídias (impresso, radio, tv, cinema), que, por sua vez, potencializam a leitura e a aprendizagem. Os conteúdos deixam de ser pacotes fechados, estáticos e passam a ser universo semiótico plural e em rede. Seus links levam o leitor a adentrar com autoria em conteúdos estáticos e dinâmicos que se apresentam em diversos gêneros textuais.

Mesmo sendo arquitetados com intencionalidade pedagógica, os conteúdos disponibilizados no AVA precisam ser encarados pelos docentes e discentes como pré-conteúdos, como proposição, fazendo jus às TICs propositivas e à hipertextualidade própria do pensamento humano. Cada sujeito que interage com o conteúdo articula-o com sua história de leitura, produzindo novas conexões e diversos desdobramentos desses conteúdos. A autoria do aprendiz pode ser potencializada com situações de aprendizagem que incentivam a prática da virtualização através de atividades de simulação. Simular é virtualizar, questionar, inventar, criar e testar hipóteses. Com a possibilidade de interatividade, o sujeito pode simular coletivamente, em colaboração com os demais sujeitos geograficamente dispersos.

\section{Considerações Finais.}

O presente texto teve por objetivo o resgate da história da educação, a partir da Paideia, conceito hegemônico dominante na história e sua possível relação com os dias atuais e a emergente educação a distância. Assim como a Paideia cristã revolucionou o significado de educação e a democratizou, colocando ao acesso de todos; nos dias atuais com o surgimento da internet, das tecnologias digitais e de todas as ferramentas disponíveis para a interação entre as pessoas, a educação a distância emerge como um fenômeno dessa nova cultura, a cibercultura. Essa forma sociocultural que emerge da relação simbiótica entre sociedade, a cultura e as novas tecnologias passam a oportunizar diversas maneiras de aprendizado.

A formação da cultura do homem, hoje perpassa por diversos canais de comunicação, formais e não formais, físicos e virtuais, e já não é, mas 
possível ignorar a urgência da educação a distância. Críticas vazias servemnos apenas como retrocesso. A nós interessa a educação no seu sentido pleno, da mesma dimensão da paideia, de educar o homem para a vida, para que ele possa formar uma sociedade justa e boa, e se essa educação antes se dava através de suportes físicos como madeira, pedra, papiro, papel e corpo hoje ela se dá através de bits - códigos digitais.

Já é hora de olharmos criticamente a educação a distância, para que esta seja construída de maneira responsável, inteligente e que essa seja uma oportunidade de fato de construção do conhecimento, e ainda de maneira colaborativa. A educação formal, em sala de aula, por palestras onde o professor se coloca como detentor do saber absoluto está convidada a se transformar. Como diz Pierre Lévy, "comunicar não é de modo algum transmitir uma mensagem ou receber uma mensagem. Isso é a condição física da comunicação. É certo que para comunicar, é preciso enviar mensagens, mas enviar mensagens não é comunicar. Comunicar é partilhar sentido." E é disso que a educação está carente atualmente, de sentido.

\section{Referências}

LEMOS, A. Cibercultura, tecnologia e vida social na cultura contemporânea. Porto Alegre: Sulina. 2002.

LÉVY, Pierre. Cibercultura. SP: Editora 34, 1999.

MARROU, Henri-Irénée (1966). História da educação na Antiguidade. Tradução de Mário Leônidas Casanova. São Paulo: Herder; Edusp.

NUNES, César. Ide, Ensinai a Todos - Os 500 anos da Pedagogia

Luterana. Editora Concórdia, Porto Alegre, 2017.

JAEGER, W. Paidéia: a formação do homem grego. Trad. Artur M. Parreira. São Paulo: Martins Fontes, 1986.

SILVA, M. Sala de aula interativa. 1a edição. Rio de Janeiro: Quartet, 2000.

SANTOS. E. Educação online como campo de pesquisa formação: potencialidades das interfaces digitais. In: SANTOS, E.; ALVES, L. (Orgs.). 
Práticas pedagógicas e tecnologias digitais. Rio de Janeiro: E-papers, 2006.

SANTOS, E. Educação Online para além da EAD: Um fenômeno da cibercultura. In: Actas do X Congresso Internacional Galego-Português de Psicopedagogia. Braga: Universidade do Minho, 2009. 